
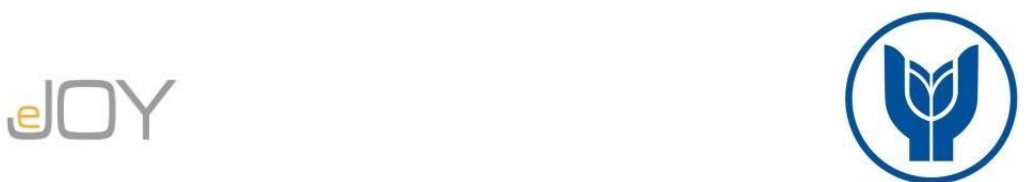

Türkmen, S., Atay, L., Türkmen, E. / Journal of Yasar University, 2018, 13/49, 22-32

\title{
Destinasyon Kişiliği, Memnuniyet ve Davranışsal Niyetler Arasındaki İlişkilerin İncelenmesi: Çanakkale Örneği
}

\section{The Examination of Relationships between Destination Personality, Satisfaction and Behavioral Intentions: Case of Çanakkale}

\author{
Serkan TÜRKMEN, Kırklareli Üniversitesi, Türkiye, serkanturkmen17@hotmail.com \\ Lütfi ATAY, Çanakkale Onsekiz Mart Üniversitesi, Türkiye, lutfiatay@yahoo.com \\ Ezgi TÜRKMEN, Çanakkale Onsekiz Mart Üniversitesi, Türkiye, ezgiturkmen@comu.edu.tr
}

\begin{abstract}
Öz: Turizm yazınında marka kișiliği kavramı yerine kullanılan destinasyon kișiliği, destinasyon markalașmasının en önemli bileșenlerinden biri olarak kabul edilmektedir. Bu çalış̧manın amact, Çanakkale'nin yerli turistler tarafindan algılanan destinasyon kişiliğini tespit etmek ve destinasyon kişiliği, ziyaret memnuniyeti ve davranışsal niyetler arasındaki ilișkileri incelemektir. Çalışma sonunda, Çanakkale'nin destinasyon kişiliği "yetkinlik-seçkinlik, samimiyet, güven ve heyecan" olmak üzere dört boyutta ortaya çıkmışttr. Destinasyon kişiliğinin ziyaret memnuniyeti ve davranışsal niyetler üzerinde olumlu bir etkisinin olduğu ortaya çıkmıştır. Ziyaret memnuniyetinin de davranışsal niyetler üzerinde olumlu bir etkisinin olduğu tespit edilmiştir.
\end{abstract}

Anahtar Sözcükler: Destinasyon Kişiliği, Ziyaret Memnuniyeti, Davranışsal Niyetler, Çanakkale

Abstract: Destination personality, which is used in exchange for brand personality concept in tourism literature, is accepted as one of the most important components of destination branding. The aim of this study is to determine the destination personality of Çanakkale perceived by domestic tourists and to examine the relationships between destination personality, visit satisfaction and visitors' behavioral intentions. In conclusion, it was found that destination personality of Çanakkale has four dimensions which are namely "competence-sophistication, sincerity, trust and excitement". Destination personality has been found to have a positive effect on visit satisfaction and visitors' behavioral intentions. In addition, visit satisfaction was found to have a positive effect on visitors' behavioral intentions.

Key Words: Destination Personality, Visit Satisfaction, Behavioral Intentions, Çanakkale

\section{Giriș}

Küreselleşmeyle birlikte ekonomik ve kültürel anlamda dünya çapında büyük değişimler yaşanmaktadır (Sünnetçioğlu vd 2012). Buna paralel olarak uluslararası turizm hareketlerinin her y1l arttığı görülmektedir. Bütün diğer sektörlerde olduğu gibi turizm sektöründe de küreselleşmenin oluşturduğu zorlu rekabet koşulları içerisinde turizm ülkeleri ve işletmeleri varlığını devam ettirme çabası içerisindedir (Hultman vd 2015). Bu rekabet şartları içerisinde birçok turizm destinasyonu kendilerini sahip olduğu fonksiyonel özellik ve değerler üzerinden pazarlamaya çalışmaktadır (Usakli ve Baloglu 2011; Murphy vd, 2007; Ekinci vd 2007). Ancak turizm sektörüne yatırım yapan ülkelerin veya bölgelerin sayısı dikkate alındığında alternatiflerin çok olması, bu tarz pazarlama çabalarını yetersiz bırakmaktadır. Birbirinden güzel ve birbirine alternatif olan destinasyonların içerisinde pazarlama ve rekabet avantajını elde edebilmek için farklılaşmaya gitmek gerekmektedir. Belirli bir destinasyonu diğerlerinden ayırt edebilmek için o destinasyonun marka haline gelmesi gerekir (Pereira vd 2014). Marka kişiliği destinasyon markasını oluşturan temel bileşenlerden biridir (Apostolopoulou ve Papadimitriou 2015). Marka kişiliği destinasyon imajı gibi diğer marka unsurlarının geliştirilmesine katkı sağlar (Hosany vd 2006) ve turizm destinasyonlarına farklı bir kimlik kazandırır (Ekinci ve Hosany 2006). Marka kişiliği, tüketicilerin algı ve deneyimlerinden oluşan psikolojik bir yapı (Sung ve Tinkham 2005) olduğu için tüketici davranışlarını etkileyen belirleyicilerden biri olarak kabul edilmektedir (Gil ve Hellgren 2011). Turist deneyimi ve duyguları ile yakın bağlantı kurduğu için turizm yazınında marka kişiliği yerine kullanılan destinasyon kişiliğ̣i, en önemli destinasyon markası bileşenlerinden biridir (Kim ve Stepchenkova 2016). Bu çalışmada Çanakkale'nin destinasyon kişiliği boyutlarının ortaya çıkarılması amaçlanmış ve destinasyon kişiliği, ziyaret memnuniyeti ve davranışsal niyetler arasındaki ilişki incelenmeye çalışılmıştır. 
Türkmen, S., Atay, L., Türkmen, E. / Journal of Yasar University, 2018, 13/49, 22-32

\section{Destinasyon Kişiliği}

Turizm yazınında araştırmacılar destinasyon markası kapsamında genellikle marka kişiliği yerine destinasyon kişiliği kavramını kullanmayı tercih etmektedirler (Usakli ve Baloglu 2011). Bu yüzden öncelikle marka kişiliği kavramını tanımlamak gerekir. Marka kişiliği, insanın sahip olduğu özellikler kümesinin marka ile ilişkilendirilmesi olarak tanımlanır (Aaker 1997, 347). Örneğin tüketici gözünde Coca-Cola markası karizmatik bir kişiliğe sahipken Pepsi modern ve heyecanlı gibi kişilik özellikleri ile ilişkilendirilebilmektedir (Lim 2013). Yine insanlara ait bütün kişilik özellikleri markalara atfedilemez. Özellikle insanların sahip olduğu bazı psikolojik özellikler (sinir hastası vb) markalara kişilik özelliği olarak uygulanması mümkün değildir(Azoulay ve Kapferer 2003).

Destinasyon kişiliği ise Hankinson $(2004,115)$ tarafından "bir yerin sahip olduğu fonksiyonel, sembolik ve deneyimsel özellikleri olarak" tanımlanmıştır. İlgili alanyazınında en çok kabul gören tanım ise Hosany vd (2006) tarafından Aaker'ın (1997) marka kişiliğinin destinasyonlara uyarlandığı tanımdır. Hosany vd (2006, 4) destinasyon kişiliğini "bir destinasyonla özdeşleştirilen insan özellikleri kümesi”" olarak tanımlamışlardır. Turistler tarafından İspanya "arkadaş canlısı", Londra "açık fikirli” ve Paris "romantik” gibi kişilik özellikleri ile ilişkilendirilmiştir (Sharma 2013, 9).

Genellikle yapılan çalışmalarda destinasyon kişiliği Aaker'ın (1997) geliştirdiği marka kişiliği ölçeğinden faydalanılarak ölçülmüştür. Aaker (1997) bu araştırmasında, 37 markanın tüketiciler tarafından algılanan marka kişiliklerini tespit etmiş ve beş boyutlu (Samimiyet, Heyecan, Yetkinlik, Seçkinlik ve Sertlik) 42 kişilik özelliğinden oluşan marka kişiliği ölçeğini geliştirmiştir. Hosany vd (2006) Aaker'ın marka kişiliği ölçeğini destinasyonlar için kullanmışlardır. Ancak 15 kişilik özelliği, destinasyonlarla ilişkilendirmeye uygun olmadığı için çalışmadan çıkarılmıştır. $\mathrm{Bu}$ çıkarma işleminden sonra 27 kişilik özelliğinden oluşan destinasyon kişiliği ölçeği (DKÖ) oluşturulmuştur.

Hosany vd (2006) İngiliz turistlerin destinasyon kişiliği algılamalarını ölçmüş ve samimiyet, heyecan ve eğlence olmak üzere destinasyon kişiliği üç boyuttan oluşmuştur. Ekinci vd (2007) Türkiye'de Akdeniz Bölgesi'nin destinasyon kişiliğini belirlemek için Alman turistler üzerinde yaptıkları çalışmada bölgenin destinasyon kişiliği eğlence, samimiyet ve heyecan olarak üç boyutta ortaya çıkmıştır. Sahin ve Baloglu (2011) İstanbul'u ilk defa ziyaret eden turistlerin İstanbul ile ilgili destinasyon kişiliği ölçmüş ve bu çalışmada yabancı turistler tarafindan İstanbul'un destinasyon kişiliği beş boyutta ortaya çıkmıştır. Bunlar; yetkinlik ve modernlik, özgünlük ve canlılık, samimiyet, karizmatik, modaya uygunluk olarak adlandırılmıştır. Usakli ve Baloglu (2011) LasVegas'ın destinasyon kişiliğinin turistler tarafından canlılık, seçkinlik, yetkinlik, çağdaş ve samimiyet olmak üzere beş boyutta algılandığını bulmuşlardır. Ye (2012) Çinli turistler üzerinde yaptığı çalışmada, Avustralya'nın destinasyon kişiliğinin samimiyet, heyecan, seçkinlik ve sertlik olmak üzere dört boyutta algılandığını tespit etmişlerdir. Chen ve Phou (2013) Kamboçya'da Angkor Tapınağı bölgesinin destinasyon kişiliğinin yabancı turistler tarafından heyecan, samimiyet, seçkinlik, sertlik ve çağdaşlık olmak üzere beş boyutta algılandığını tespit etmişlerdir. Artuğer ve Çetinsöz (2014) Alanya'nın destinasyon kişiliğinin yabancı turistler tarafından heyecan verici, sert, yeterlilik ve samimiyet olarak dört boyutta algılandığını bulmuşlardır.

Destinasyon kişiliği çalışmalarında aynı ölçekler kullanılmasına rağmen destinasyonları kişiliklerinin farklı boyutlarda ortaya çıktığı görülmektedir. Destinasyonlar farklı karakteristik özelliklere sahip olduğu için her bölge yada şehir için destinasyon kișiliği farklı boyutlarda ortaya çıkmaktadır (Artuğer ve Çetinsöz 2014; Souiden 2017). Bazen aynı destinasyonun farklı kişiler tarafından değişik kişilik özellikleri ile tanımlanması dahi mümkün olabilir (Torlak ve Uzkurt 2005; Dölarslan 2012; Kim ve Stepchenkova 2016).

\section{Destinasyon Kişiliğinin Memnuniyet ve Davranışsal Niyetler Arasındaki İlişsisi}

Yönetim ve pazarlama yazınında araştırmacılar genellikle aşağıda yer alan üç konu üzerinde ortak görüş bildirmektedir (Hultman vd 2015, 2227). Bunlar;

1) Mevcut müşterilerin korunması gerektiği,

2) Tavsiye veya ağızdan ağza iletişimin etkin bir tutundurma faaliyeti olduğu,

3) Müşteri memnuniyetinin gelecekteki tüketici davranışları üzerinde önemli bir etkisinin olduğudur.

Destinasyon kişiliğinin de pazarlama yazınının fikir birliği yaptı̆̆ı bu üç husus üzerindeki etkisi araştırılması gereken bir konudur. Destinasyon kişiliği, belirli turistik çekiciliklere sahip bir yerin rakiplerinden farklılaşmasını sağlayan önemli bir faktördür (Pitt vd 2007). Ayrıca destinasyon ve turist arasında duygusal bağlar kurulmasını sağlayarak turistlerin o bölgeye yönelik sadakatini ve yeniden ziyaret eğilimini arttırmaktadır (Ekinci vd 2007; Chen ve Phou 2013).

Usakli ve Baloglu (2011) LasVegas'ındestinasyon kişiliği tespit ettikleri çalışmada destinasyon kişiliğinin davranışsal niyetleri olumlu yönde etkilediğini tespit etmişlerdir. Baloglu vd (2014) Jamaika'nın destinasyon kişiliğini ortaya koydukları çalışmada, destinasyon kişiliğinin turistlerin destinasyonu yeniden ziyaret etme ve tavsiye etme niyetleri üzerinde olumlu bir etkisinin olduğu sonucuna ulaşmışlardır. Xie ve Lee'nin (2013) yaptığı çalışmada ise destinasyon kişiliğinin sadece tavsiye etme niyeti üzerinde olumlu etkisi olduğu ortaya çıkmıştır. Genellikle yapılan çalışmalarda, destinasyon kişiliği ile davranışsal niyetler arasında olumlu yönde bir ilişki olduğu sonucuna varılmıştır (Ekinci vd 2007; Kılıç ve Sop 2012; Xie ve Lee 2013; Lee ve Kang 2013; Kim ve Lee 2015; Zeugner-Roth ve Zabkar 2015). 
Hultman vd (2015) Tayvanlı turistler üzerinde yaptıkları çalışmada, algılanan destinasyon kişiliğinin seyahat memnuniyeti üzerinde, yeniden ziyaret eğilimi ve tavsiye etme davranışı olarak kabul edilen davranışsal niyetler üzerinde olumlu etkisi olduğu sonucuna ulaşmışlardır. Umur ve Eren'in (2016) Kapadokya'da yaptıkları çalışmada da destinasyon kişiliği ziyaretçi memnuniyetini ve davranışsal niyetleri olumlu yönde etkilediği ortaya çıkmıştır. Ayrıca bu çalışmada ziyaret memnuniyetinin davranışsal niyetleri olumlu yönde etkilediği sonucuna da ulaşılmıştır.

\section{Yöntem}

Araştırmanın evrenini, Çanakkale'de 25-26 Mart 2017 tarihleri arasında Çanakkale Savaşları Gelibolu Tarihi Alan Başkanlığı himayesinde ve isim sponsorluğunda yapılan Çanakkale Bisiklet Turu organizasyonuna katılan kişiler oluşturmaktadır. Bu organizasyona 2043 resmi kayıtlı bisikletçi katılmıştır ve bu kişilerin \% 95'i Türkiye'nin çeşitli illerinden organizasyona dahil olmuştur. Çalışmada veri toplama aracı olarak anket yöntemi kullanılmıştır. Bu ankette yer alan ifadelerle Çanakkale'nin destinasyon kişiliği boyutları, ziyaret memnuniyeti ve davranışsal niyetler ölçülerek, destinasyon kişiliği, ziyaretçi memnuniyeti ve davranışsal niyetler arasındaki ilişkiler ortaya çıkarılmaya çalışılmıştır. Anketin birinci bölümünde destinasyon kişiliği, ikinci bölümünde davranışsal niyetler ve üçüncü bölümünde ise ziyaret memnuniyeti ile ilgili değişkenler yer almaktadır. Bu üç bölümde yer alan değişkenler Likert ölçeğinin 5'li derecelendirmesi ile ölçülmüştür (1: kesinlikle katılmıyorum; 5 kesinlikle katılıyorum).

Hosany vd (2006), Aaker'ın (1997) geliştirdiği 42 ifadeli marka kişiliği ölçeğini destinasyonlara uyarlayarak 27 ifadeli destinasyon kişiliği ölçeğini (DKÖ) oluşturmuşlardır. Hosany vd (2006) tarafından uyarlanan bu DKÖ, birçok araştırmacı tarafından kullanılmış ve destinasyon kişiliğini ölçmede güvenilir ve geçerli bir ölçek olarak kabul edilmiştir (Ekinci vd 2007; Sahin ve Baloglu 2011; Ye 2012; Li ve Kaplanidou 2013; Baloglu vd 2014; Bilim ve Bilim 2014; Papadimitriou vd 2015). Bu çalışmada da Çanakkale'nin destinasyon kişiliğini ölçmek için Hosany vd tarafından oluşturulan DKÖ kullanılmıştır. Ayrıca daha önce Çanakkale'yi ziyaret eden 10 kişi ile görüşülmüş ve onlardan Çanakkale destinasyonunu bir kişi olarak hayal etmeleri istenmiştir. Çanakkale'yi bir kişi olarak hangi kişilik özellikleri ile tanımladıkları sorulmuş ve dokuz yeni kişilik özelliği (barışçıl, ferah, huzurlu, sevimli, temiz, eğitimli, doğal, kültürlü, açık fikirli) daha ankete eklenmiştir. Sonuç olarak ankete katılan ziyaretçilerden "Çanakkale'yi turistik açıdan bir kişi olarak düşünüp" ankette yer alan 36 kişilik özelliği ile Çanakkale’yi ilişkilendirmeleri istenmiştir. Ankette kullanılan ve üç ifadeden oluşan ziyaret memnuniyeti ölçeği ve beş ifadeden oluşan davranışsal niyetler ölçeği İlban vd (2016) çalışmasından alınmıştır.

Çanakkale dışındaki illerden gelerek bisiklet organizasyonuna katılarak Çanakkale’yi deneyimleyen ziyaretçilerin tamamına anket dağıtılmıştır. Gönüllü olarak anketi dolduran 429 kişi araştırmanın örneklemini oluşturmuştur. Elde edilen anketlerden 29 tanesi çeşitli nedenlerden dolayı araştırmaya dahil edilmemiştir. Geriye kalan 400 anket araştırmada analiz etmek için kullanılmıştır. Araştırmanın modeli Şekil 1'de yer almaktadır

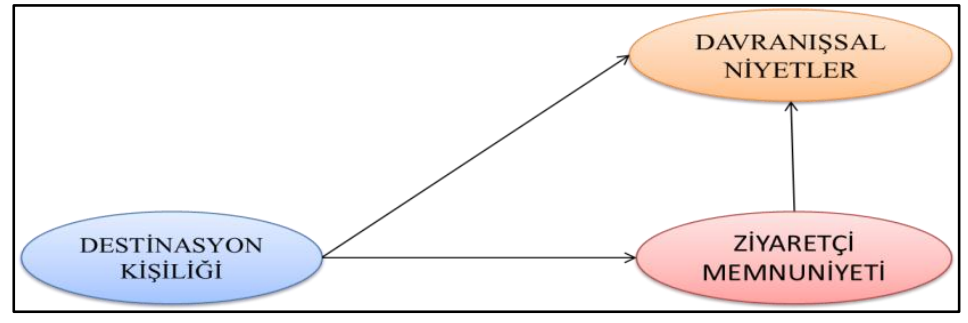

Şekil 1: Araştırmanın Modeli

Elde edilen veriler sonrasında araştırmadaki ölçeklere öncelikle açıklayıcı ve daha sonra doğrulayıcı faktör analizi yapılmıştır. Sonraki aşamada yapısal eşitlik modeli (YEM) test edilmiş ve çok boyutlu modelin geçerli bir model olup olmadığı iyilik uyum değerleriyle analiz edilmiştir. Yapısal eşitlik modelinin geçerliliğinin belirlenmesinde kikare/serbestlik derecesi oranı, CFI, NFI, TLI, SRMR ve RMSEA indeksleri kullanılmıştır. SPSS 20.0 ve Amos 21.0 paket programları verilerin analiz yapılmasında kullanılmıştır.

\section{Araştırmanın Bulguları}

Tanımlayıcı istatistiklere göre araştırmaya katılanların yaş dağılımları \% 50'si 18-25 yaş, \% 31,8'i 26-35 yaş, \% 11,8'i 36-45 yaş, \% 4,5'i 46-55 yaş ve \% 2'si de 56 ve üstü yaş grubunda ortaya çıkmıştır. Katılımcıların \% 35,3'ü (141 kişi) kadınlardan ve \% 64,8'i (259 kişi) erkeklerden oluşmaktadır. Katılımcıların \% 57'si lisans, \% 17,3'ü lisansüstü, \% 15,5'i önlisans, \% 8'i lise ve dengi seviyede eğitim almıştır. Katılımcıların aylık gelir dağılımları ele alındığında \% 18'inin 1500 ve altı, \% 32,8'inin 1501-3000 TL, \% 18'3'ünün 3001-4500 TL, \% 16,3'ünün 4501-6000 TL ve \% 14,8'inin 6001 ve üzeri TL gelir grubunda yer aldığı tespit edilmiştir. Katılımcıların \% 15'8'i daha önce Çanakkale'yi hiç ziyaret etmezken \% 20,5'i bir, \% 16'sı iki, \% 11'i üç ve \% 36,9'u dört ve daha fazla kez Çanakkale'yi ziyaret etmişlerdir. 


\subsection{Açıklayıcı Faktör Analizi (AFA)}

Çanakkale'yi ziyaret eden kişilerin algıladıkları destinasyon kişiliğini, ziyaret memnuniyetini ve davranışsal niyetlerini belirlemeye yönelik hazırlanan ölçekte yer alan değişkenlerin yapı geçerliliğini incelemek için AFA yapılmıştır. Bunun için öncelikle verilerin normal dağılıp dağılmadığına bakılmıştır. Araştırma verilerine Kolmogorov-Smirnov testi yapılmış ve $\mathrm{p}>, 05$ düzeyinde veriler anlamlı çıkmıştır. Bu yüzden verilerin basıklık-çarpıklık değerlerine bakılmıştır. Basıklık çarpıklık değerlerinin tamamı $(+1,5)$ ila $(-1,5)$ arasında çıktı̆̆ı için verilerin normal dağıldığı kabul edilmiştir (Tabachnick ve Fidell 2013). Verilerin faktör analizine uygunluğu örneklem yeterliliği (KMO) katsayısı ve BarlettSphericity testi ile incelenmiştir. Faktör analizinin yapılabilmesi kapsamında KMO alt değeri için 0,70 (Altunışı vd 2012) ve Barlett's sphericity testi için $\leq 0,05$ değerleri temel alınmıştır (Akkoyunlu vd 2010).

Tablo 1'de Destinasyon Kişiliği Ölçeğine (DKÖ) ait KMO ve Bartlett's sphericity testi sonuçları verilmiştir ve KMO değerinin ,907 olduğu ve Bartlett testine göre yaklaşık ki kare $(\chi 2)$ değerinin 3347,776 ve anlamlılık düzeyinin $\mathrm{p}=, 000$ sifir olduğu görülmektedir. Bu sonuç ölçeğin faktör analizine uygun olduğunu göstermektedir.

DKÖ'ye yapılan faktör analizi sonrasında 9 madde faktör yükünün düşük olması ve 10 madde binişik madde olması sebebiyle analizden çıkarılmış ve DKÖ dört boyutta ortaya çıkmıştır. Birinci, ikinci ve dördüncü boyutlar Aaker'ın (1997) marka kişiliği ölçeğindeki boyutların isimleri dikkate alarak isimlendirilmiştir. Birinci boyutta yer alan 6 kişilik özelliği orijinal ölçekte (Aaker 1997) yetkinlik ve seçkinlik boyutlarında yer aldığı bu boyuta yetkinlikseçkinlik adı verilmiştir. Ayrıca birinci boyut ölçeği en yüksek düzeyde açıklayan $(\% 43,142)$ boyut olmuştur. İkinci boyut samimiyet ve dördüncü boyut heyecan olarak adlandırılmıştır. Üçüncü boyutta "Barışç1, Huzurlu, Açık fikirli ve Eğitimli” kişilik özellikleri yer aldığı için bu boyut güven olarak adlandırılmıştır.

Tablo 1.Çanakkale'nin Destinasyon Kişiliğine İlişkin AFA

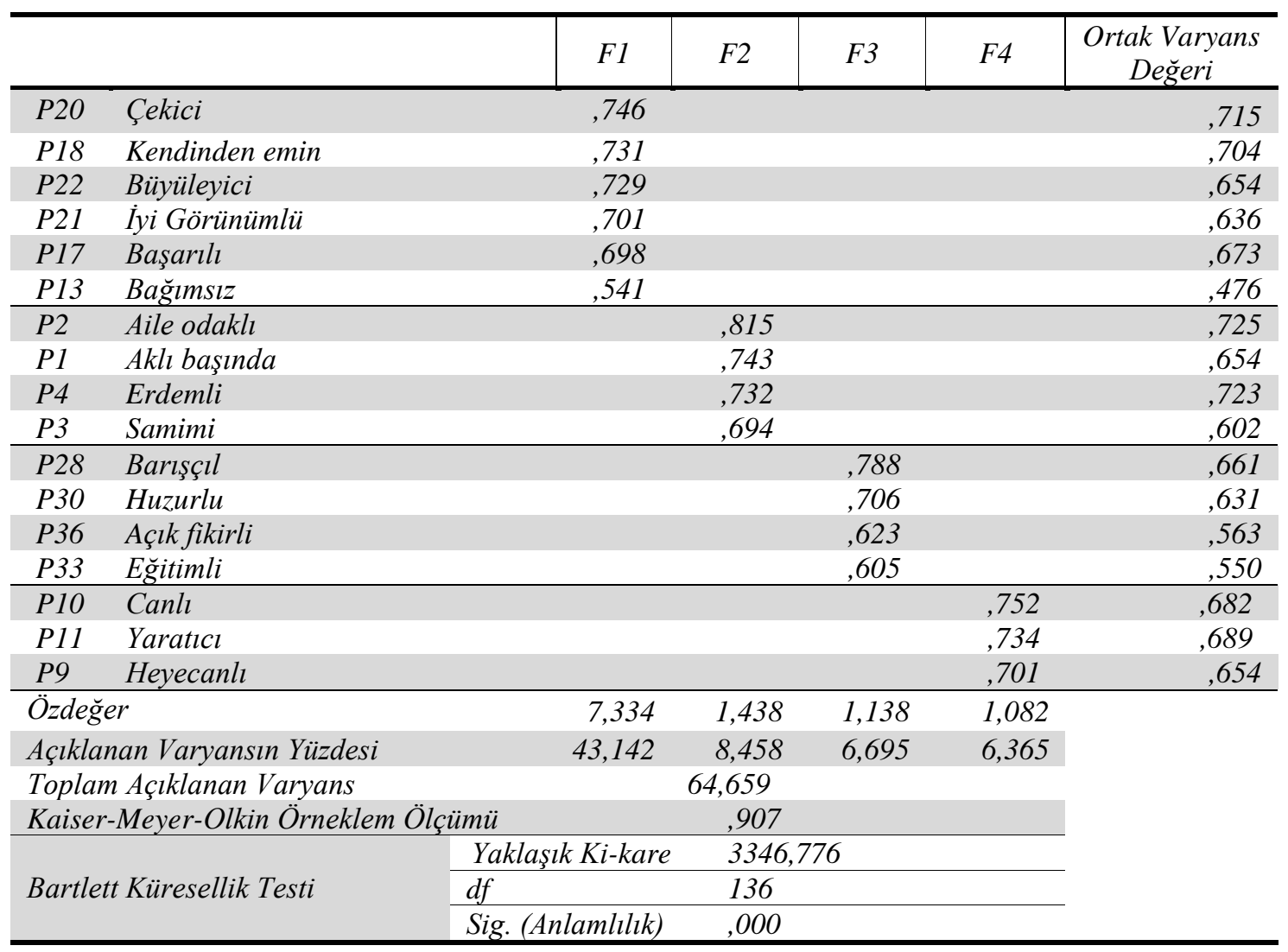

Tablo 2'de ziyaret memnuniyetine iliş̧kin ve Tablo 3'te davranışsal niyetlere ilişkin AFA sonuçları verilmiştir. Her iki ölçek de tek boyutta ortaya çıkmıştır. Ziyaret memnuniyeti ölçeği \% 83, 405 düzeyinde ve davranışsal niyetler ölçeği $\%$ 65,611 düzeyinde açıklanmıştır. 
Türkmen, S., Atay, L., Türkmen, E. / Journal of Yasar University, 2018, 13/49, 22-32

Tablo 2.Ziyaret Memnuniyetine İlişkin AFA

\begin{tabular}{|c|c|c|c|c|c|}
\hline \multicolumn{4}{|c|}{ Ifadeler } & Faktör 1 & Ortak Varyans Dĕgeri \\
\hline$S 2$ & \multicolumn{3}{|c|}{ Çanakkale'yi ziyaret etmekle çok doğru bir karar verdim. } & ,920 &, 846 \\
\hline S1 & \multicolumn{3}{|c|}{ Genel olarak Çanakkale ziyaretimden memnunum. } & ,916 & ,839 \\
\hline S3 & \multicolumn{3}{|c|}{ Çanakkale ziyareti beklentilerimi karşıladı. } & ,904 &, 817 \\
\hline \multicolumn{3}{|c|}{$\ddot{\text { Özdeğer }}$} & 2,502 & & \\
\hline \multicolumn{3}{|c|}{ Açıklanan Varyansın Yüzdesi } & 83,405 & & \\
\hline \multicolumn{3}{|c|}{ Toplam Açıklanan Varyans } & 83,405 & & \\
\hline \multicolumn{3}{|c|}{ Kaiser-Meyer-Olkin Örneklem Ölçümü } & ,752 & & \\
\hline \multirow{3}{*}{\multicolumn{2}{|c|}{ Bartlett Küresellik Testi }} & Yaklaşık Ki-kare & 743,795 & & \\
\hline & & $d f$ & 3 & & \\
\hline & & Sig. (Anlamlılık) &, 000 & & \\
\hline
\end{tabular}

Tablo 3. Davranışsal Niyetlere ilişkin AFA

\begin{tabular}{|c|c|c|c|c|c|}
\hline \multicolumn{4}{|c|}{ Ifadeler } & Faktör 1 & Ortak Varyans Dĕgeri \\
\hline$B I 1$ & \multicolumn{3}{|c|}{ Çanakkale'yi gelecekte tekrar ziyaret etmek isterim. } & ,799 & 638 \\
\hline$B I 2$ & \multicolumn{3}{|c|}{ Çanakkale hakkında olumlu ifadeler kullanırım. } & 900 & 810 \\
\hline$B I 3$ & \multicolumn{3}{|c|}{$\begin{array}{l}\text { Arkadaşlarımalyakınlarıma Çanakkale 'yi ziyaret } \\
\text { etmelerini tavsiye ederim. }\end{array}$} & ,885 & ,783 \\
\hline BI4 & \multicolumn{3}{|c|}{ Çanakkale'yi diğer insanlara anlatmaktan gurur duyarım. } & ,829 & ,686 \\
\hline$B I 5$ & \multicolumn{3}{|c|}{ Çanakkale hakkında olumsuz bir düşüncem yoktur. } &, 602 & ,363 \\
\hline & 3,281 & & \\
\hline \multicolumn{3}{|c|}{ Toplam Açıklanan Varyans } & 65,611 & & \\
\hline \multicolumn{3}{|c|}{ Kaiser-Meyer-Olkin Örneklem Ölçümü } & ,822 & & \\
\hline \multirow{3}{*}{\multicolumn{2}{|c|}{ Bartlett Küresellik Testi }} & Yaklaşık Ki-kare & 1073,801 & & \\
\hline & & $d f$ & 10 & & \\
\hline & & Sig. (Anlamlılık) & 000 & & \\
\hline
\end{tabular}

\section{2. Ölçüm Modeli (DFA)}

AFA sonucunda elde edilen boyutların sınanması ve araştırma modeline ilişkin boyutlarla ne dereceparalellik gösterdiğini istatistiksel olarak açıklamak için DFA yapılmıştır. Analiz sonucunda Tablo 4'te yer alan değerlerde görüldüğü gibi destinasyon kişiliği ölçüm modeli için gözlenen değişkenler örtük değişkenleri istenilen düzeyde temsil etmiştir. Uyum iyiliği değerlerine bakıldığında da araştırmada kullanılan veri seti araştırma modelini desteklediği görülmüştür.

Tablo 4. DKÖ Standart Yükler, Ölçüm Hataları, t Değeri ve Uyum İyilikleri Tablosu

\begin{tabular}{|c|c|c|c|c|c|c|}
\hline Boyutlar & & işilik Özellikleri & $\begin{array}{c}\text { St. Reg. } \\
\text { Katsaylsl }\end{array}$ & $S M C$ & $t$ değgeri & $P$ \\
\hline \multirow{6}{*}{$\begin{array}{l}\text { Yetkinlik- } \\
\text { Seçkinlik }\end{array}$} & $P 20$ & Çekici &, 765 & ,239 & 15,055 & $* * *$ \\
\hline & P18 & Kendinden emin & ,756 &, 284 & 14,194 & $* * *$ \\
\hline & $P 22$ & Büyüleyici & ,743 &, 362 & $\lambda 1$ 'e sabitlenmiştir. & $* * *$ \\
\hline & $P 21$ & İyi Görünümlü & ,734 &, 244 & 14,345 & $* * *$ \\
\hline & P17 & Başarılı & ,700 &, 364 & 12,985 & $* * *$ \\
\hline & $P 13$ & Bağımsız & ,647 & ,455 & 12,098 & $* * *$ \\
\hline \multirow[t]{4}{*}{ Samimiyet } & $P 2$ & Aile odaklı & ,696 & ,379 & 13,821 & $* * *$ \\
\hline & $P 1$ & Aklı başında & ,688 & ,379 & 13,911 & $* * *$ \\
\hline & $P 4$ & Erdemli & ,839 &, 187 & ג1'e sabitlenmiştir. & $* * *$ \\
\hline & $P 3$ & Samimi & ,723 &, 269 & 14,840 & $* * *$ \\
\hline \multirow[t]{4}{*}{ Güven } & $P 28$ & Barışçıl &, 544 & ,371 & 9,536 & $* * *$ \\
\hline & P30 & Huzurlu & ,630 &, 223 & 10,7977 & $* * *$ \\
\hline & P36 & Açık fikirli & ,748 & ,292 & 13,648 & $* * *$ \\
\hline & P33 & Ĕgitimli & ,744 &, 241 & ג1'e sabitlenmiştir. & $* * *$ \\
\hline Heyecan & $P 10$ & Canll & 685 & ,387 & ג l'e sabitlenmiştir. & $* * *$ \\
\hline
\end{tabular}


Türkmen, S., Atay, L., Türkmen, E. / Journal of Yasar University, 2018, 13/49, 22-32

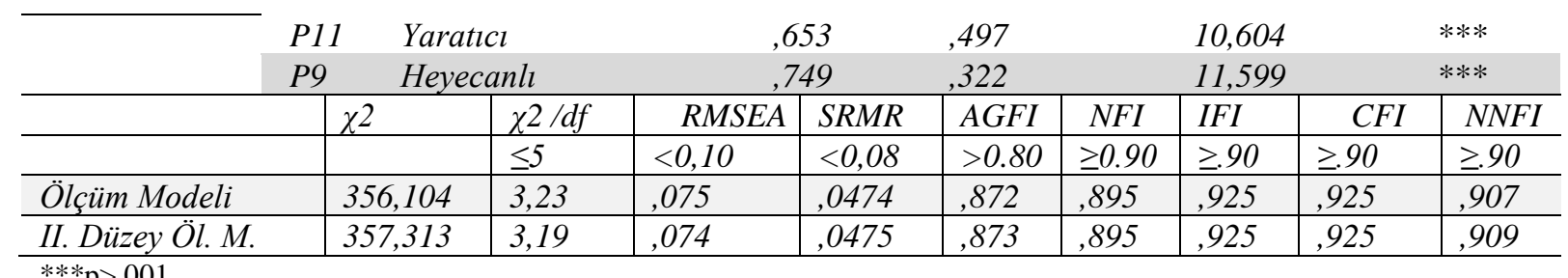

$* * * \mathrm{p}>, 001$

Modelin güvenilirliğini belirlemek için yapılan değerlendirmede, Cronbach Alpha değerinin ve CR (Composite Reliability-CR) katsayısının 0,70'ten, AVE (Average Variance Extracted-AVE) değerinin de 0,5'ten büyük olması gerekmektedir (Fornell ve Larcker 1981; Hair vd 2010). Tablo 5'e göre gözlenen değişkenler ait oldukları boyutları yeterli oranda ve birbirleri ile tutarlı bir biçimde açıklamaktadır. Yapısal geçerlilik ile ilgili kesin kararı vermek için ayrım ve benzeşim geçerliliğine bakılmıştır. Ayrım geçerliliği için bir boyutun AVE değerinin boyutlar arasındaki korelasyonların en büyüğünün karesinden büyük olması gerekir (Fornell ve Larcker, 1981). Bu koşul sadece samimiyet boyutu için sağlanamamıştır. Fakat ayrım geçerliliğinin bir diğer göstergesi de faktörler arasındaki korelasyonların 0,85'ten küçük bir değer olmasıdır (Klein 2015; Chou vd 2002). Tablo 5'e bakıldığında bu koşulun da sağlandığ1 görülmektedir. Benzeşim geçerliliği için AVE değerinin ,50'den büyük ve CR değerinin de AVE değerinden büyük (CR>AVE; AVE>0,5) olması gerekmektedir (Hair vd 2010). Tablo 5'te görüldüğü gibi bu koşullar da sağlanmaktadır.

Tablo 5. DKÖ Ait Güvenilirlik ve Geçerlilik Sonuçları

\begin{tabular}{|l|c|c|c|c|c|c|c|}
\hline & C. Alp. & $C R$ & AVE & 1 & 2 & 3 & 4 \\
\hline (1)Seçkinlik-Yetkinlik &, 874 &, 906 &, 618 &, 662 & & & \\
\hline (2)Samimiyet &, 826 &, 877 &, 643 &, 688 &, 473 & & \\
\hline (3)Güven &, 776 &, 863 &, 616 &, 814 &, 609 &, 662 & \\
\hline (4)Heyecan &, 736 &, 783 &, 547 &, 740 &, 605 &, 659 &, 547 \\
\hline
\end{tabular}

NOT: Tablodaki AVE $=\Sigma \lambda 2 / \Sigma \lambda 2+\Sigma \varepsilon$ ve $C R=(\Sigma \lambda) 2 /(\Sigma \lambda) 2+\Sigma \varepsilon$ formülleriyle hesaplanmiştır.

Tablo 6'da ziyaret memnuniyeti ölçüm modeline ait sonuçlar verilmiştir. Ölçekteki bütün maddelerin t-değerleri p<,001 düzeyinde anlamlıdır. Modelin yapısal geçerliliğini belirlemek için yapılan değerlendirmede; CR değeri ,918 düzeyinde Cronbach Alpha değeri ,897 ve AVE değeri de ,971 düzeyinde tespit edilmiştir. Model tek boyuttan oluştuğu için ayrım geçerliliği yapılamamıştır. Benzeşim geçerliliğine bakıldığında AVE ve CR değerleri istenilen düzeyde ve CR değerinin AVE değerinden büyük olduğu ortaya çıkmıştır (CR=,971>AVE=,918; AVE> ,50).

Tablo 6. Ziyaret Memnuniyeti Ölçeğine Ait Standart Yükler, Ölçüm Hataları, t Değeri ve Uyum İyilikleri Tablosu

\begin{tabular}{|c|c|c|c|c|c|c|c|c|c|}
\hline \multicolumn{4}{|c|}{ Ziyaret memnuniyeti } & $\begin{array}{l}\text { St. } \text { Reg. } \\
\text { Katsaylsl } \\
\end{array}$ & $S M C$ & \multicolumn{3}{|c|}{$t$ değgeri } & $P$ \\
\hline \multicolumn{4}{|c|}{$\begin{array}{l}\text { (S2)Çanakkale'yi ziyaret etmekle çok doğru bir } \\
\text { karar verdim. }\end{array}$} & ,886 &, 047 & \multicolumn{3}{|c|}{21,031} & $* * *$ \\
\hline \multicolumn{4}{|c|}{$\begin{array}{l}\text { (S1)Genel olarak Çanakkale ziyaretimden } \\
\text { memnunum. }\end{array}$} & 873 &, 062 & \multicolumn{3}{|c|}{20,784} & $* * *$ \\
\hline \multicolumn{4}{|c|}{ (S3)Çanakkale ziyareti beklentilerimi karşıladı. } & ,841 & 093 & \multicolumn{3}{|c|}{ ג1'e sabitlenmiştir. } & $* * *$ \\
\hline & $\chi^{2}$ & $\chi^{2} / d f$ & $\begin{array}{l}\text { RMSE } \\
A\end{array}$ & $S R M R$ & $A G F I$ & $N F I$ & IFI & $C F I$ & $N N F I$ \\
\hline & & $\leq 5$ & $<0,10$ & $<0,08$ & $>0.80$ & $\geq 0.90$ & $\geq .90$ & $\geq .90$ & $\geq .90$ \\
\hline Ölçüm Modeli & \multicolumn{9}{|c|}{ Modelin serbestlik derecesi “0” olduğu için hesaplanamamıştır. } \\
\hline
\end{tabular}

Tablo 7'de davranışsal niyetler ölçüm modeline ait sonuçlar verilmiştir. Modelden "BI4” ifadesi, ölçüm hata değeri (,91) çok yüksek olduğu için çıkarılmıştır. Uyum iyiliklerine göre veri seti modeli mükemmel bir şekilde desteklemiştir. Ölçekteki bütün maddelerin t-değerleri $\mathrm{p}<, 001$ düzeyinde anlamlıdır. Modelin yapısal geçerliliğini belirlemek için yapılan değerlendirmede; CR değeri ,910 düzeyinde Cronbach Alpha değeri ,785 ve AVE değeri de ,725 düzeyinde tespit edilmiştir. Model tek boyuttan oluştuğu için ayrım geçerliliği yapılamamıştır. Benzeşim geçerliliğine bakıldığında AVE ve CR değerlerinin istenilen düzeyde ve CR değerinin AVE değerinden büyük olduğu ortaya çıkmıştır $(\mathrm{CR}=, 910>\mathrm{AVE}=, 725 ; \mathrm{AVE}>, 50)$. 
Türkmen, S., Atay, L., Türkmen, E. / Journal of Yasar University, 2018, 13/49, 22-32

Tablo 7. Davranışsal Niyetler Ölçeğine Ait Standart Yükler, Ölçüm Hataları, t Değerleri ve Uyum İyilikleri Tablosu

\begin{tabular}{|c|c|c|c|c|c|c|c|c|c|c|c|}
\hline \multicolumn{5}{|c|}{ Davranışsal Niyetler } & \multicolumn{2}{|c|}{$\begin{array}{l}\text { St. Reg. } \\
\text { Katsaylsl } \\
\end{array}$} & $S M C$ & \multicolumn{3}{|c|}{$t$ değgeri } & $P$ \\
\hline$B I 1$ & \multicolumn{4}{|c|}{$\begin{array}{l}\text { Çanakkale'yi gelecekte tekrar ziyaret } \\
\text { etmek isterim. }\end{array}$} & \multicolumn{2}{|c|}{,728 } &, 161 & \multicolumn{3}{|c|}{$\lambda 1$ 'e sabitlenmiştir. } & $* * *$ \\
\hline$B I 2$ & \multicolumn{4}{|c|}{$\begin{array}{l}\text { Çanakkale hakkında olumlu ifadeler } \\
\text { kullanırım. }\end{array}$} & \multicolumn{2}{|c|}{,890 } &, 059 & \multicolumn{3}{|c|}{18,024} & $* * *$ \\
\hline$B I 3$ & \multicolumn{4}{|c|}{$\begin{array}{l}\text { Arkadaşlarıma/yakınlarıma Çanakkale'yi } \\
\text { ziyaret etmelerini tavsiye ederim. }\end{array}$} & \multicolumn{2}{|c|}{, 842} &, 070 & \multicolumn{3}{|c|}{10,289} & $* * *$ \\
\hline \multirow[t]{3}{*}{$B I 5$} & \multicolumn{3}{|c|}{$\begin{array}{l}\text { Çanakkale hakkında olumsuz bir } \\
\text { düşüncem yoktur. }\end{array}$} & & \multicolumn{2}{|c|}{,481 } &, 568 & \multicolumn{3}{|c|}{8,228} & \\
\hline & & $\chi^{2}$ & $\chi^{2 / d f}$ & & MSEA & $S R M R$ & $A G F I$ & $N F I$ & IFI & $C F I$ & NNFI \\
\hline & & & $\leq 5$ & $<0,1$ & & $<0,08$ & $>0.80$ & $\geq 0.90$ & $\geq .90$ & $\geq .90$ & $\geq .90$ \\
\hline \multicolumn{2}{|c|}{ Ölçüm Modeli } &, 500 &, 500 &, 000 & &, 0057 & ,994 & ,999 & 1,00 & 1,00 & ,996 \\
\hline
\end{tabular}

Bu çalışmada destinasyon kişiliği, ziyaret memnuniyeti ve davranışsal niyetler arasındaki ilişkileri ortaya çıkarmak için YEM analizinden faydalanılmıştır. Şekil 2'de ve Tablo 8'de araştırma modeline ait parametre değerleri yer almaktadır. Araştırma modeli sekiz adet uyum iyiliği kriterinden yararlanılarak test edilmiştir. Yalnızca NFI değeri kabul edilen değerin biraz altında çıkmıştır. Diğer uyum iyiliği değerlerinin tamamı kabul edilebilir düzeydedir. Araştırmanın YEM analizi sonuçlarına göre destinasyon kişiliğinin ziyaret memnuniyeti $(\beta=0,701 \mathrm{t}=9,385 \mathrm{p}<0,001)$ ve davranışsal niyetler $(\beta=0,233 \mathrm{t}=4,046 \mathrm{p}<0,001)$; ziyaret memnuniyetinin davranışsal niyetler $(\beta=0,755 \mathrm{t}=11,493$ $\mathrm{p}<0,001)$ üzerinde istatistiksel açıdan anlamlı ve olumlu bir etkisi olduğu ortaya çıkmıştır. Ayrıca destinasyon kişiliğ davranışsal niyetleri ,529 düzeyinde dolaylı olarak da etkilemektedir. Araştırma modelinde bağımsız değişkenlerin bağımlı değişkenler üzerindeki açıklama gücü $\left(\mathrm{R}^{2}\right)$ değerlendirildiğinde destinasyon kişiliği ziyaret memnuniyetindeki değişimin\% 49'unu ve destinasyon kişiliği ile ziyaret memnuniyeti davranışsal niyetlerdeki değişimin \% 87'sini açıklamaktadır.

Tablo 8. YEM Analizi Sonuçları ve Uyum İyilikleri

\begin{tabular}{|c|c|c|c|c|c|c|c|c|c|}
\hline \multicolumn{5}{|c|}{ Değişkenler Arası İlişki } & \multicolumn{2}{|c|}{$\begin{array}{c}\text { St. Reg. } \\
\text { Katsaylst }\end{array}$} & S.E. & t Değeri & $P$ \\
\hline \multicolumn{2}{|c|}{ Ziyaret memnuniyeti } & $<---$ & \multicolumn{2}{|c|}{ Destinasyon Kişiliği } & \multicolumn{3}{|c|}{,079 } & 9,385 & $* * *$ \\
\hline \multicolumn{2}{|c|}{ Davranışsal Niyetler } & $<--$ & \multicolumn{2}{|c|}{ Ziyaret Memnuniyeti } &, 755 & \multicolumn{2}{|c|}{, 056} & 11,483 & $* * *$ \\
\hline \multicolumn{2}{|c|}{ Davranışsal Niyetler } & $<---$ & \multicolumn{2}{|c|}{ Destinasyon Kişiliği } &, 233 & \multicolumn{2}{|c|}{052} & 4,046 & $* * *$ \\
\hline & $\chi^{2}$ & $\chi^{2} / d f$ & RMSEA & SRMR & $A G F I$ & $N F I$ & $I F I$ & $C F I$ & NNFI \\
\hline & & $\leq 5$ & $<0,10$ & $<0,08$ & $>0.80$ & $\geq 0.90$ & $\geq .90$ & $\geq .90$ & $\geq .90$ \\
\hline YEM Modeli & 707,387 & 2,935 &, 070 & 0498 &, 842 &, 880 & ,917 & ,917 &, 905 \\
\hline
\end{tabular}




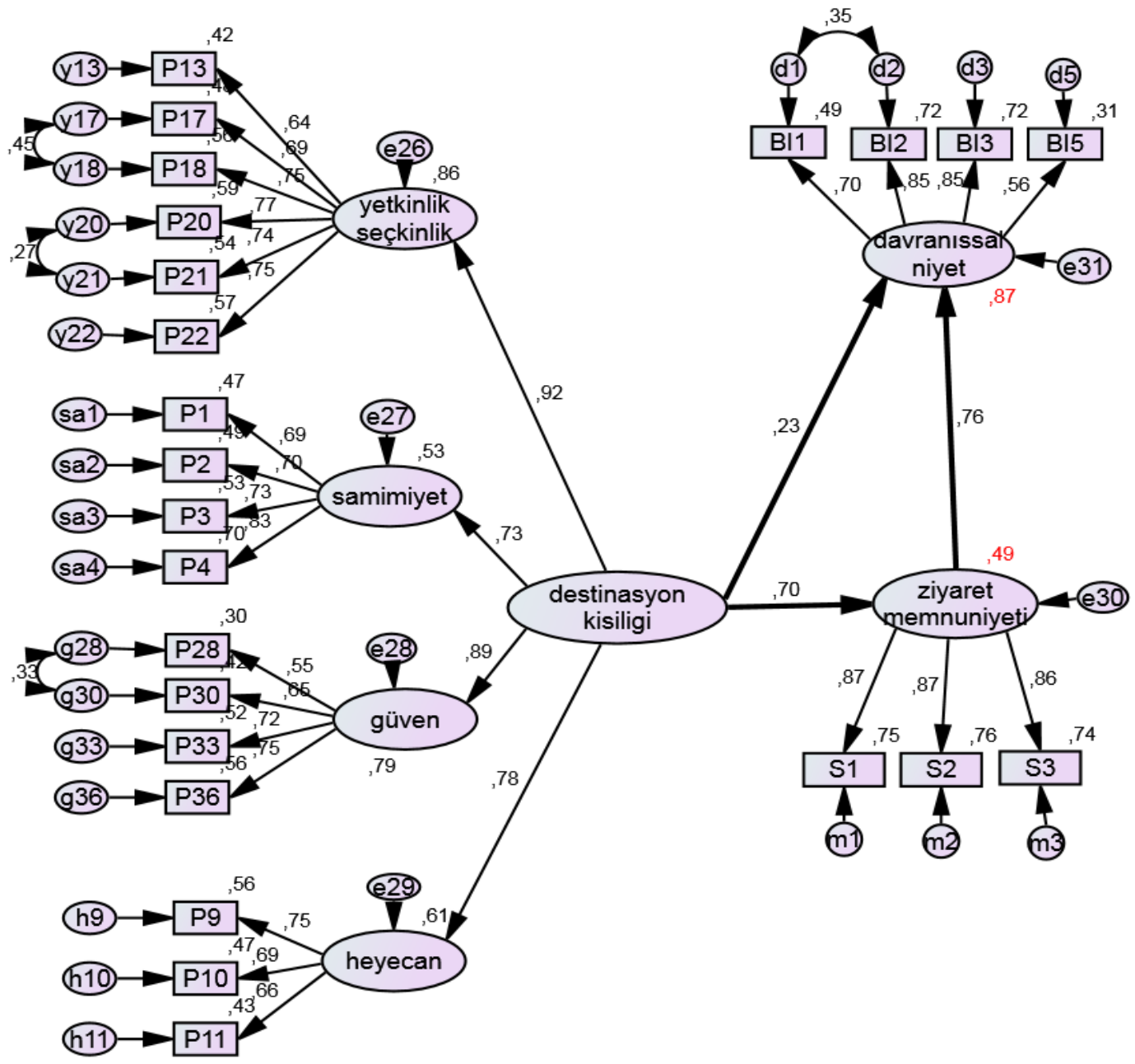

Şekil 2. Araştırma Modeline Ait Parametre Değerleri

\section{Sonuç ve Öneriler}

Çanakkale tarihi, kültürel ve doğal çekiciliklere sahip bir destinasyon olduğu gibi yerli ve yabancı turistler tarafından tercih edilen bir destinasyondur (Sözen 2007).Bu çalışmada öncelikli olarak Çanakkale'nin Türk ziyaretçiler algısındaki destinasyon kişiliği boyutları ortaya çıkarılmaya çalışılmıştır. Daha sonradestinasyon kişiliği, ziyaret memnuniyeti ve davranışsal niyetler arasındaki ilişkiler incelenmiştir.

Araştırma sonucunda Çanakkale'nin destinasyon kişiliği yetkinlik-seçkinlik, samimiyet, güven ve heyecan olmak üzere dört boyutta ortaya çıkmıştır. Güven olarak adlandırılan destinasyon kişiliği boyutu 'barışçıl, huzurlu, eğitimli ve açık fikirli’ kişilik özelliklerinden meydana gelmektedir. Bu boyut tamamen Çanakkale destinasyonuna özel bir destinasyon kişiliği boyutu olarak ortaya çıkmıştır. Ancak AFA analizinde Çanakkale'nin destinasyon kişiliğini en yüksek düzeyde açıklayan boyut (,43) yetkinlik-seçkinlik boyutu olmuştur. Murphy vd (2007a) Queensland'da ve Murphy vd (2007b) Whithsunday Adası'nda yaptıkları çalışmalarda da orijinal MKÖ'de seçkinlik ve yetkinlik boyutu altında yer alan kişilik özelikleri tek bir boyutta toplanmıştır. Bu çalışmada da benzer bir sonuç çıktığı için bu boyuta yetkinlik-seçkinlik boyutu denmiştir. Yapılan birçok destinasyon kişiliği çalışmasında farklı boyutlar ortaya çıkmıştır. Destinasyon kişiliğinin iki boyutta (Papadimitrou vd 2013; Apostolopoulou ve Papadimitriou 2014), üç boyutta (Ekinci vd 2007; Klabi 2012; Rojas-Mendez vd 2013; Bilim ve Bilim 2014), dört boyutta (Murphy vd 2007a; Muphy vd 2007b; Forristal ve Lehto 2009; Xie ve Lee 2013; Artuğer ve Çetinsöz 2014) ve beş boyutta (Opoku 2009; Yeh vd 2010; Usakli ve Baologlu 2011; De Mayo ve Jain 2013; Chen ve Phou 2013; Aguilar vd 2014) ortaya çıktığ1 çalışmalar bulunmaktadır. Bu çalışmada da Çanakkale'nin destinasyon kişiliği dört boyutta ortaya çıkmıştır. Yapılan araştırmalarda destinasyon kişiliğinin farklı boyutlarda ortaya çıkması normal bir sonuçtur. Çünkü her destinasyonun kendine has değişik özellikleri bulunmasından dolayı farklı kişilik özellikleri ile algılanmaktadır. Daha öncede ifade edildiği gibi aynı markaların veya destinasyonların farklı insanlar tarafından başka kişilik özellikleri ile algılanabileceğini ifade edilmektedir (Torlak ve Uzkurt 2005; Dölarslan 2012; Kim ve Stepchenkova 2016).

Çalışmada destinasyon kişiliği, ziyaret memnuniyeti ve davranışsal niyetler arasında istatistiksel açıdan anlamlı ilişkiler ortaya çıkmıştır. Ziyaret memnuniyetinin beklendiği gibi turistlerin davranışsal niyetlerini $(\beta=0,755 \mathrm{t}=11,493$ $\mathrm{p}<0,001)$ olumlu yönde etkilediği ortaya çıkmıştır. Davranışsal niyetler bir tüketicinin belirli bir ürünü deneyimledikten 
sonra gelecekte o ürünle ilgili neler yapabileceğini gösteren davranışlar bütünüdür (İlban vd 2016). Bu çalışmada davranışsal niyetler ile kişinin gelecekte destinasyonu tekrar ziyaret etmesi ve yakınlarına destinasyon hakkında olumlu tavsiyelerde bulunması ifade edilmeye çalışılmıştır. Araştırmada memnuniyetin davranışsal niyetleri etkilemesi daha önce yapılan araştırmalarda ortaya çıkan sonuçlarla paralellik göstermektedir (Kozak ve Rimmington 2000; Yoon ve Uysal 2005; Zabkar vd 2010; Shi vd 2014; Hultman vd 2015; Umur ve Eren 2016).

Araştırmanın bağımsız değişkeni olan destinasyon kişiliğinin, hem ziyaret memnuniyetini $(\beta=0,701 \mathrm{t}=9,385 \mathrm{p}<$ $0,001)$ hem de davranışsal niyetleri $(\beta=0,233 \mathrm{t}=4,046 \mathrm{p}<0,001)$ olumlu yönde etkilediği ortaya çıkmıştır. Hultman vd (2015) yaptığı araştırmada destinasyon kişiliğinin memnuniyeti, tekrar ziyaret etme ve tavsiye etme niyetini olumlu yönde etkilediği bulunmuştur. Araştırmada destinasyon kişiliğinin memnuniyet ve davranışsal niyetleri olumlu yönde etkilediği sonucu daha önce yapılan çalışmalarla benzerlik göstermiştir (Usakli ve Baloglu 2011; Kılıç ve Sop 2012; Baloglu vd 2014; Kim ve Lee 2015).

Ziyaret memnuniyeti algılanan destinasyon kişiliği tarafından \% 49 oranında $\left(\mathrm{R}^{2}=, 491\right)$ ve davranışsal niyetler; destinasyon kişiliği ve ziyaret memnuniyeti tarafından $\% 87$ oranında $\left(\mathrm{R}^{2}=, 872\right)$ oranında açıklanmaktadır. Dolayısıyla bu çalışmada elde edilen sonuçlar doğrultusunda, destinasyon kişiliğinin turist davranışlarını tahmin etmede önemli bir değişken olduğu ortaya çıkmıştır. Destinasyon yöneticilerinin farklı bir destinasyon kimliği ve güçlü bir destinasyon markası oluşturmaları için destinasyon kișiliği konusu üzerinde durmaları gerekmektedir. Çanakkale açısından da potansiyel ve mevcut ziyaretçilerin destinasyona yönelik tutum ve algılarının sürekli ölçülmesi önem arz etmektedir. Destinasyon kişiliğinin turist davranışlarını etkilediğigöz önünde bulundurulduğundadestinasyon kişiliğinin hangi boyutlarda oluşturulması gerektiği yönünde destinasyon yöneticilerinin karar vermesi ve o yönde çalışması gerekir. Lim (2013) destinasyon kişiliğinin mevcut turistler açısından turistik deneyim esnasında işletmelerle, çalışanlarla ve turistik değerlerle kurulan temaslar sonucunda ortaya çıktığını ifade etmektedir. Fakat o destinasyonu ziyaret etmemiş potansiyel turistler açısından destinasyonla ilgili duyumlar, reklam-pazarlama faaliyetleri ve medyada yer alan haberler sonucunda kişilerin zihninde bir destinasyon kişiliği oluşmaktadır (Cai 2002). Yapılacak reklam ve pazarlama iletişimi faaliyetlerinin içerikleri, oluşturulmak istenen destinasyon kişiliği algısı ile uyumlu olmalıdır. Ayrıca destinasyonun sahip olduğu turistik çekicilikler (kültür, deniz-kum-güneş vb) dikkate alınarak farklı pazar bölümlerine göre farklı destinasyon kişiliği algısı oluşturma faaliyetleri yürütmek faydalı olabilir. Ayrıca ağızdan ağza iletişsim olarak da adlandırılan tavsiye davranışı ile destinasyon kişiliği arasında önemli bir ilişki vardır. Bu yüzden mevcut turistlerin elde ettiği deneyimleri paylaşması potansiyel turistler açısından referans oluşturmakta ve potansiyel turistlerin destinasyon kişiliği algılamalarını şekillendirebilmektedir.

Birçok çalışmada olduğu gibi bu çalışmanın da bazı kısıtları bulunmaktadır. Bu çalışmada belirli bir ziyaretçi grubu örneklem olarak belirlenmiş ve örneklemin tamamı yerli turistlerden oluşmaktadır. Çanakkale'yi ziyaret eden çok sayıda yabancı ziyaretçi olduğu dikkate alındığında, yabancı ziyaretçilerin Çanakkale'nin destinasyon kişiliğine yönelik algılarını tespit etmeye yönelik bir araştırma yapılabilir. 
Türkmen, S., Atay, L., Türkmen, E. / Journal of Yasar University, 2018, 13/49, 22-32

\section{KAYNAKÇA}

Aaker, J. L. 1997. "Dimensions of Brand Personality.” Journal of Marketing Research 34(3): 347-356.

Akkoyunlu, B., Soylu, M. Y., ve Çağlar, M. 2010. "Üniversite Öğrencileri İçin 'Sayısal Yetkinlik Ölçeği’ Geliştirme Çalışması." Hacettepe Üniversitesi Eğitim Fakültesi Dergisi 39: 10-19.

Altunışık, R., Coşkun, R., Bayraktaroğlu, S., ve Yıldırım, E. 2012. Sosyal Bilimlerde Araştırma Yöntemleri: SPSS Uygulamalı (7. Baskl). İstanbul: Avcı Ofset.

Apostolopoulou, A., and Papadimitriou, D. 2015. "The Role of Destination Personality in Predicting Tourist Behaviour: Implications for Branding Mid-sized Urban Destinations." Current Issues in Tourism 18(12): 1132-1151.

Artuğer, S., ve Çetinsöz, B.Ç. 2014. "Destinasyon İmajı İle Destinasyon Kişiliği Arasındaki İlişkiyi Belirlemeye Yönelik Bir Araştırma." İşletme Araştırmaları Dergisi 6 (1): 366-384.

Azoulay, A., and Kapferer, J. N. 2003. "Do BrandPersonalityScalesReallyMeasureBrandPersonality?" Journal of Brand Management 11(2): 143-155.

Baloglu, S., Henthorne, T. L., and Sahin, S. (2014). "Destination Image and Brand Personality of Jamaica: A Model of Tourist Behavior." Journal of Travel \& Tourism Marketing 31 (8): 1057-1070.

Bilim, Y., and Bilim, M. B. 2014. "Does A Destination Have Personality? Personality and Image Issues of A Destination." Athens Journal of Tourism 1(2): 121- 134.

Cai, Liping A. 2002. "Cooperative Branding for Rural Destinations." Annals of TourismResearch 29(3): $720-742$.

Chou, S. C., Boldy, D. P., and Lee, Y. H. 2002. "Measuring Job Satisfaction in Residential Aged Care." International Journal for Quality in Health Care 14(1): 49-54.

Chen, C. F., and Phou, S. 2013. "A Closer Look at Destination: Image, Personality, Relationship and Loyalty." Tourism Management 36: 269- 278.

De Moya, M., and Jain, R. 2013. "When Tourists AreYour "Friends": Exploring the Brand Personality of Mexico and Brazil on Facebook." Public Relations Review 39(1): 23-29.

Dölarslan, E. Şahin. 2012. "Bir Marka Kişiliği Ölçeği Değerlendirmesi.” Ankara Üniversitesi SBF Dergisi 67(2): 1-28.

Ekinci, Yuksel, and Hosany, Sameer. 2006. "Destination Personality: An Application of Brand Personality to Tourism Destinations." Journal of Travel Research 45: 127-139

Ekinci, Y., Sirakaya-Turk, E., and Baloglu, S. 2007. "Host Image and Destination Personality.” Tourism Analysis 12(5/6): 433-446.

Fornell, C., and Larcker, D. F. 1981. "Evaluating Structural Equation Models with Unobservable Variables and Measurement Error". Journal of Marketing Research 18(1): 39-50.

Forristal, L. J., and Lehto, X. Y. 2009. "Place Branding With Native Species: Personality as A Criterion.” Place Branding and Public Diplomacy 5(3): 213-225.

Gil, A. G., and Hellgren, D. 2011. "Brand Personality: Impact on Brand Trustand Consumer Preferences: A comparative Study of Germany and Sweden.” Master Thesis of Umeå School of Business, Biblioteksgränd/Sweden.

Hair, J. F., Black, W. C., Babin, B. J., andAnderson, R. E. 2010. Multivariate Data Analysis: Global Perspective. New Jersey: Pearson Education, Prentice Hall.

Hankinson, G. 2004. "Relational Network Brands: Towards A Conceptual Model of Place Brands.” Journal of Vacation Marketing 10(2): 109-121.

Hosany, S., Ekinci, Y., and Uysal, M. 2006. "Destination Image and Destination Personality: An Application of Branding Theories to Tourism Places." Journal of Business Research 59(5): 638-642.

Hultman, M., Skarmeas, D., Oghazi, P., and Beheshti, H. M. 2015. "Achieving Tourist Loyalty through Destination Personality, Satisfaction, and Identification.” Journal of Business Research 68(11): 2227-2231.

İlban, M. O., Bezirgan, M., ve Çolakoğlu, F. 2016. "Termal Otellerde Algılanan Hizmet Kalitesi, Memnuniyet ve Davranışsal Niyetler Arasındaki İlişkilerin İncelenmesi: Edremit Örneği.” Anatolia: Turizm Araştırmaları Dergisi 27(2): 181-194.

Kılıç, B., and Sop, S. A. 2012. "Destination Personality, Self-congruity and Loyalty." Journal of Hospitality Management and Tourism 3(5): 95-105.

Kim, H., and Stepchenkova, S. 2016. "Understanding Destination Personality through Visitors' Experience: A Crosscultural Perspective." Journal of Destination Marketing \& Management, Accessed May 28, https://doi.org/10.1016/j.jdmm.2016.06.010

Kim, H. B., and Lee, S. 2015. "Impacts of City Personality and Image on RevisitIntention." International Journal of Tourism Cities, 1(1): 50-69.

Klabi, F. 2012. "The Predictive Power of Destination-Personality-Congruity on Tourist Preference: A Global Approach to Destination Image Branding." Leisure/Loisir 36(3-4): 309-331.

Kline, R. B. 2015. Principles and Practice of Structural Equation Modeling (4th Ed.). London: Guilford Publications.

Kozak, M., and Rimmington, M. 2000. "Tourist Satisfaction with Mallorca, Spain, as an Off-Season Holiday Destination." Journal of Travel Research 38(3): 260-269.

Lee, H. J., and Kang, M. S. 2013. "The Effect of Brand Personality on Brand Relationship, Attitude, and Purchase Intention with A Focus on Brand Community." Academy of Marketing Studies Journal, 17(2): 85-97.

Li, X. R., and Kaplanidou, K. K. 2013. "The Impact Of the 2008 Beijing Olympic Games on China's Destination Brand A US-Based Examination.” Journal of Hospitality\&Tourism Research 37(2): 237-261. 
Türkmen, S., Atay, L., Türkmen, E. / Journal of Yasar University, 2018, 13/49, 22-32

Lim, Seonghwan. 2013. The Effect of Destination Personality and Self Destination Congruity on Visitors' Intentions. Master Thesis of Science, the Office of Graduate Studies of Texas A\&M University.

Murphy, L., Moscardo, G., and Benckendorff, P. 2007. "Using Brand Personality to Differentiate Regional Tourism Destinations." Journal of Travel Research 46(1): 5-14.

Murphy, L., Benckendorff, P., and Moscardo, G. 2007a. "Destination Brand Personality: Visitor Perceptions of a Regional Tourism Destination.” Tourism Analysis 12(5-6): 419-432.

Murphy, L., Benckendorff, P., and Moscardo, G. 2007b. "Linking Travel Motivation, Tourist Self-Image and Destination Brand Personality." Journal of Travel \&Tourism Marketing 22(2): 45-59.

Opoku, R. A. 2009. "Mapping Destination Personality in Cyberspace: An Evaluation of Country Web Sites Using Correspondence Analysis." Journal of Internet Commerce 8(1-2): 70-87.

Papadimitriou, D., Apostolopoulou, A., and Kaplanidou, K. 2015. "Destination Personality, Affective Image, and Behavioral Intentions in Domestic Urban Tourism." Journal of Travel Research 54(3): 302-315.

Pereira, R. L. G.,Correia, A. D. J. H., and Schutz, R. L. A. 2014. "Destination Brand Personality: Searching for Personality Traits on Golf-Related Websites.” Anatolia 25(3): 387-402.

Pitt, L. F., Opoku, R., Hultman, M., Abratt, R., and Spyropoulou, S. 2007. "What I Say about Myself: Communication of Brand Personality by African Countries." Tourism Management, 28(3): 835-844.

Rojas-Méndez, J. I., Murphy, S. A., and Papadopoulos, N. 2013. "The US Brand Personality: A Sino Perspective." Journal of Business Research 66(8): 1028-1034.

Sharma, Rajesh Kumar. 2013. Brand Personality of Tourism Destination: The Case of Kathmandu, Nepal. Master's Thesis in International Business. University Of Norland, Bodø, Norway.

Shi, Y., Prentice, C. and He, W. 2014. "Linking Service Quality, Customer Satisfaction and Loyalty in Casinos, Does Membership Matter?” International Journal of Hospitality Management 40: 81-91.

Sözen, M. Ö. 2007. “1982 Sonrasında Türkiye'de Uygulanan Turizm Politikalarının Çanakkale Turizmine Etkileri.” Sosyo Ekonomi 6(6): 63-88.

Sahin, S., and Baloglu, S. 2011. Brand Personality and Destination Image of Istanbul. Anatolia-An International Journal of Tourism and Hospitality Research 22(01): 69-88.

Souiden, N., Ladhari, R., \& Chiadmi, N. E. 2017. “Destination Personality and Destination Image.” Journal of Hospitality and Tourism Management 32: 54-70.

Sung, Y., and Tinkham, S. F. 2005. Brand Personality Structures in the United Statesand Korea: Common and Culturespecific Factors. Journal of Consumer Psychology, 15(4): 334-350.

Sünnetçioğlu, S., Can, A., ve Durlu-Özkaya, F. "Yavaş Turizmde Coğrafi İşaretlemenin Önemi.” 13. Ulusal Turizm Kongresi'nde sunulmuştur, Antalya, 6-9 Aralık, 2012.

Tabachnick, B. G. And Fidell, L.S. 2013. Using Multivariate Statistics (6th Ed.). Boston: Pearson.

Torlak, Ö. ve Uzkurt, C. 2005. "Kola Markası Kişiliklerinin Üniversite Öğrencileri Tarafından Algılanması.” Dokuz Eylül Üniversitesi İsletme Fakültesi Dergisi 6(2): 15-31.

Umur, M., ve Eren, D . 2016. "Destinasyon İmaj1 Ve Destinasyon Kişiliğinin, Ziyaretçi Memnuniyeti Ve Geleceğe Yönelik Ziyaretçi Davranışı Üzerine Etkisi: Kapadokya Örneği.” Kırıkkale Üniversitesi Sosyal Bilimler Dergisi, 6(1): 271-294.

Usakli, A.,andBaloglu, S. 2011. "Brand Personality of Tourist Destinations: An Application of Self-congruity Theory." Tourism Management 32(1): 114-127.

Xie, K. L., and Lee, J. S. 2013. "Toward the Perspective of CognitiveDestination Image and Destination Personality: The Case of Beijing." Journal of Travel \&Tourism Marketing 30: 538-556.

Ye, S. 2012. "The Impact of Destination Personality Dimensions on Destination Brand Awareness and Attractiveness: Australia as a Case Study.” Turizam: Znanstveno-Stručni Časopis 60(4): 397-409.

Yeh, Pi-Hua, Liu, Chyong-Ru, and Yeh, Shih-Shuo. 2010.” Loyalty and Its Relationship with Travel Motivation, Brand Personality, and Congruity of Self Image." International Journal of Agricultural Travel and Tourism 1(1): 94-106.

Yoon, Y. and Uysal, M. 2005. “An Examination of theEffects of Motivation and Satisfaction on Destination Loyalty: A Structural Model," Tourism Management 26(1): 45-56.

Zeugner-Roth, K. P., and Žabkar, V. 2015. "Bridging the Gap between Country and Destination Image: Assessing Common Facets and Their Predictive Validity." Journal of Business Research 68(9): 1844-1853.

Zabkar, V., Brenčič, M. M. And Dmitrovic, T. 2010. "Modelling Perceived Quality, Visitor Satisfaction and Behavioural Intentions at the Destination Level." Tourism Management 31(4): 537-546. 